\section{Sump syndrome and biliary adenocarcinoma 40 years after surgical choledochoduodenal fistula}

A 74-year-old icteric female presented with abdominal cramps, chills, and night sweats, and reported a 20-lb weight loss since the symptoms started 3 months previously. Past medical history included cholecystectomy, which was performed in 1965 due to gallbladder stones; the patient had been asymptomatic for the past 40 years.

An endoscopic retrograde cholangiopancreatography confirmed suspected choledocholithiasis, and after removal of several stones the bile duct was stented with two plastic prostheses. Furthermore, duodenoscopy identified a large choledochoduodenal fistula, enabling a view of the stents in the main bile duct ( $\bullet$ Figure 1). The margins of the fistula showed villous appearance of the mucosa, and biopsies confirmed tubulo-villous adenoma in this area. Cholangioscopy demonstrated a mass obstructing the main bile duct ( Figure 2 ), and histologic examination confirmed simultaneous biliary adenocarcinoma. Investigation of ancient medical records revealed the surgical creation of a choledochoduodenal fistula after cholecystectomy in 1965, ensuring biliary drainage for decades. The fistula was the precondition for the development of a "sump syndrome", with deposition of stones and debris in the bile duct distal to the fistula and proximal to the papilla.

Several risk factors contribute to the rising incidence of cholangiocarcinoma but chronic cholangitis has been shown to be the most relevant precondition [1]. Larger anastomoses between the bile duct and the duodenum, as frequently performed many decades ago, may constantly lead to large-volume reflux into the biliary system, causing chronic irritation of the endothelium. Over the course of decades, chronic inflammation may lead to the formation of adenomatous tissue and finally progress to adenocarcinoma [2]; we demonstrated both conditions in this patient.

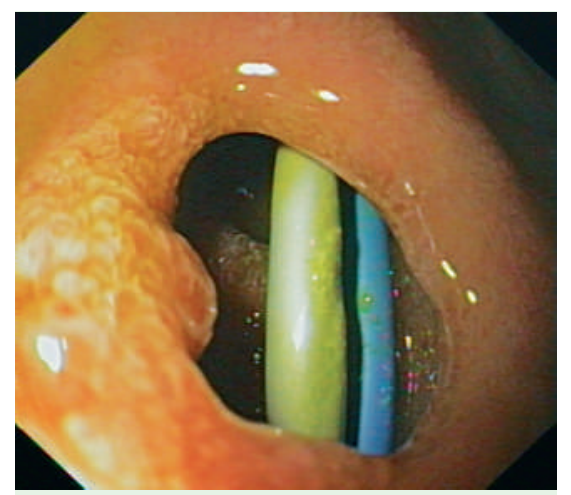

Figure 1 Choledochoduodenal fistula enabling a view of the plastic prostheses in the main bile duct. Biopsies from the villous margin of the fistula revealed tubulo-villous adenoma.

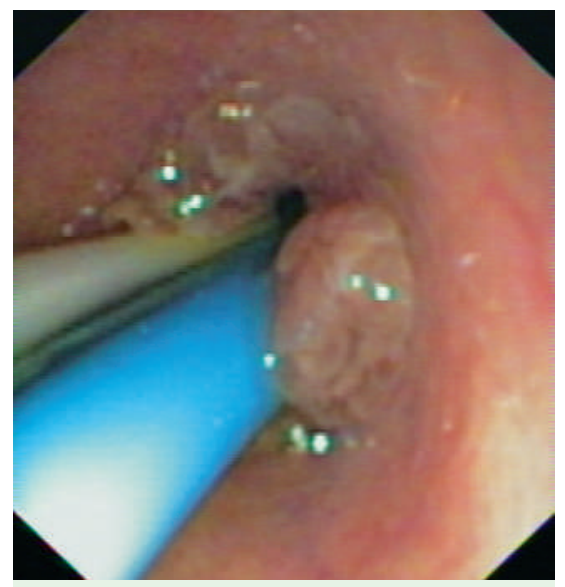

Figure 2 Cholangioscopy via the fistula demonstrating a central mass obstructing the main bile duct.

Therefore, longstanding subclinical cholangitis could be assumed to be a precancerous lesion and may cause malignant transformation [3], and biliary-enteric fistula may be a predisposing condition for the later development of cholangiocarcinoma [4].

Endoscopy_UCTN_Code_CCL_1AZ_2AC

\section{Mecklenburg, R. Scheubel, H. Messmann}

Third Medical Department, Klinikum Augsburg, Germany

\section{References}

1 Malhi H, Gores GJ. Cholangiocarcinoma: Modern advances in understanding a deadly old disease. J Hepatol 2006; 45: 856-867

2 Tocchi A, Mazzoni G, Liotta G et al. Late development of bile duct cancer in patients who had biliary-enteric drainage for benign disease: a follow-up study of more than 1,000 patients. Ann Surg 2001; 234: $210-$ 214

3 Shimonishi T, Sasaki M, Nakanuma Y. Precancerous lesions of intrahepatic cholangiocarcinoma. J Hepatobiliary Pancreat Surg 2000; 7: 542-550

4 Kuroki T, Fukuda K, Tajima Yet al. Parapapillary choledochoduodenal fistula associated with cholangiocarcinoma. J Hepatobiliary Pancreat Surg 2005; 12: $143-146$

\section{Bibliography}

DOI 10.1055/s-2007-966402

Endoscopy 2007; 39: E194

(c) Georg Thieme Verlag KG Stuttgart · New York . ISSN 0013-726X

\section{Corresponding author}

\section{Mecklenburg, MD}

III. Medizinische Klinik

Klinikum Augsburg

Stenglinstr. 2

86156 Augsburg

Germany

Fax: +49-821-400-3331

Email: ingo.mecklenburg@med.uni-muenchen.de 